\title{
Strategi pengembangan BUMDes di Kecamatan Pangkalan Lesung Kabupaten Pelalawan, Riau
}

\author{
Anjar Setiana, Almasdi Syahza*, Suarman \\ Program Studi Pendidikan Ekonomi, Fakultas Keguruan dan Ilmu Pendidikan \\ Universitas Riau
}

\begin{abstract}
Abstrak: Penelitian ini bertujuan untuk merumuskan strategi pengembangan BUMDes di Kecamatan Pangkalan Lesung. Hasil penelitian diketahui bahwa kekuatan pengelolaan BUMDes di Kecamatan Pangkalan Lesung sudah baik, motivasi yang tinggi oleh anggota untuk berbisnis, SDM cukup banyak karena di pedesaan, sarana dan prasarana gratis yang digunakan BUMDes, lokasi strategis di tengah masyarakat. Sisi negatifnya adalah kurangnya tenaga ahli tentang BUMDes, kualitas sumber daya manusia yang kurang, sarana dan prasarana yang masih kurang memadai, serta keterbatasan infrastruktur. Peluangnya adalah perkembangan teknologi yang semakin maju, dukungan dari pemerintah daerah, memiliki potensi desa yang sangat bagus untuk dikembangkan, pasokan barang semakin lengkap dan persepsi BUMDes di Kecamatan Pangkalan Lesung cukup baik. Hasil analisis matriks SWOT diperoleh rumusan strategi pengembangan BUMDes di Kecamatan Pangkalan Lesung yaitu: 1) Meningkatkan penjualan dengan cara meningkatkan pasokan barang yang lebih lengkap; 2) Menjalin kerjasama dengan mitra bisnis: dan 3) Meningkatkan pelayanan kepada anggota sesuai kebutuhannya.
\end{abstract}

Katakunci: strategi pengembangan, analisis SWOT, BUMDes

\begin{abstract}
This research aims to formulate a BUMDes development strategy in Pangkalan Lesung sub-district. The results of the research, it is known that the strength is BUMDes management in Pangkalan Lesung subdistrict has been good, high motivation by members for business, human resources quite a lot because in the countryside, free facilities and Infrastructure used by BUMDes, strategic location in the middle of the community. The downside is the lack of experts about BUMDes, the lack of quality of human resources, facilities and infrastructure is still not adequate, and infrastructure limitations. Opportunity is the development of increasingly advanced technology, support from local governments, has excellent village potential to be developed, the supply of goods is more complete and the perception of BUMDes in Pangkalan Lesung Subdistrict is quite good. The results of the SWOT matrix analysis show that the BUMDes development strategy is: 1) Increase sales by increasing the supply of more complete goods; 2) Establish cooperation with business partners: and 3) Improve services to members according to their needs.
\end{abstract}

Keywords: development strategy, SWOT analysis, BUMDes

JEL Classification: $O 18 ; R 11 ; M 38$

* Penulis koresponden 


\section{PENDAHULUAN}

Salah satu dalam memacu pertumbuhan ekonomi, kebijaksanaan ekonomi harus menganut paradigma baru dimana pemberdayaan ekonomi rakyat harus menjadi perhatian utama. Pemberdayaan ekonomi rakyat juga berarti membangun ekonomi pedesaan dengan lebih baik (Syahza dan Suarman 2013). Menurut Syahza dan Henny (2010) mengatakan juga untuk mewujudkan tujuan pengembangan ekonomi kerakyatan, terutama di sektor industri kecil maka perlu dipersiapkan kebijakan strategis untuk memperbesar atau mempercepat pertumbuhan sektor industri kecil, khususnya peningkatan pendapatan dan kesejahteraan masyarakat melalui koperasi. Salah satu cara untuk mencapai tujuan tersebut adalah pengembangan koperasi yang terencana dengan baik dan terkait dengan pembangunan sektor ekonomi lainnya terutama di pedesaan. Fitriska (2017) mengatakan untuk mewujudkan desa yang mandiri, maka diperlukan sumber pendapatan bagi desa yang berasal dari desa tersebut. Kemandirian yang dimaksud adalah proses yang dilakukan pemerintah desa bersama masyarakat untuk melakukan kegiatan dalam rangka pemenuhan kebutuhannya sesuai kemampuan yang dimiliki dalam mendorong pembangunan ditingkat desa, pemerintah memberikan kewenangan kepada pemerintah desa untuk mengelola daerahnya secara mandiri, salah satunya adalah melalui lembaga ekonomi yang berada ditingkat desa.

Pengembangan basis ekonomi di pedesaan sudah semenjak lama dijalankan oleh pemerintah melalui berbagai program. Bentuk kelembagaan sebagaimana disebutkan diatas dinamakan Badan Usaha Milik Desa (BUMDes). Peraturan Menteri Pembangunan Daerah Tertinggal, dan Transmigrasi Republik Indonesia, Nomor 4 tahun 2015, tentang Pendirian, Pengurusan dan Pengelolaan, dan Pembubaran Badan Usaha Mllik Desa Pendirian BUM Desa dimaksudkan sebagai upaya menampung seluruh kegiatan di bidang ekonomi dan/atau pelayanan umum yang dikelola oleh Desa dan/atau kerja sama antar-Desa. Badan Usaha Milik Desa (BUMDes) merupakan lembaga usaha desa yang dikelola oleh masyarakat dan pemerintahan desa dalam upaya memperkuat perekonomian desa dan dibentuk berdasarkan kebutuhan dan potensi desa.

Pemerintah Kecamatan Pangkalan Lesung melalui desa-desanya mendirikan BUMDes pada tahun 2017, untuk memfasilitasi masyarakat yang sedang membutuhkan pekerjaan dan meningkatkan perekonomian serta untuk memompa perekonomian masyarakat dengan adanya kebijakan pendirian BUMdes. Yang mana setiap BUMdes memiliki beberapa usaha sepeti simpan pinjam yang digunakan untuk membuka usaha, dan pengadaan barang dan jasa yang dibutuhkan masyarakat desa. Adapun BUMDes yang terdapat di Kecamatan Pangkalan Lesung yang berjumlah 9 BUMDes yang yang mana terletak disetiap desa yang ada di Kecamatan Pangkalan Lesung memiliki nama dan jenis usaha yang dijalankan sesuai AD/ART bahwa di kecamatan ini sampai sekarang BUMDes telah berkembang sebanyak 9 buah yang berada pada desa yang ada di Kecamatan ini. 
Sulaksana dan Irni (2019) menyatakan bahwa usaha BUMDes Mitra Sejahtera masih tergolong baru dan dalam tahap percobaan oleh karena itu BUMDes Mitra Sejahtera dibutuhkan strategi pengembangan agar usaha BUMDes tersebut dapat berjalan dengan baik, mengembangkan jaringan usaha lain dan diharapkan manfaat dari usaha bumdes tersebut dapat dirasakan oleh seluruh lapisan masyarakat sehingga dapat berdampak bagi kesejahteraan masyarakat desa dan meningkatkan pendapatan desa. Sejalan dengan hasil penelitian Syahza dkk (2021), BUMDes sangat berperan untuk meningkatkan ekonomi masyarakat pedesaan. Savitri dkk (2021), percepatan ekonomi pedesaan juga dapat dilakukan melalui pengembangan usaha mickro kecil dan menengah (UMKM). Syahza dkk (2020), dalam upaya percepatan ekonomi di wilayah pesisir dan masyarakat di lahan gambut, peran BUMDes dan UMKM sangat diperlukan.

BUMDes di Kecamatan Pangkalan Lesung dan usaha yang dijalankannya masih tergolong baru dan mengingat betapa strategisnya potensi BUMdes oleh karena itu BUMDes di Kecamatan Pangkalan Lesung maka dibutuhkan strategi pengembangan agar usaha BUMDes tersebut dapat berjalan dengan baik, mengembangkan jaringan usaha lain dan diharapkan manfaat dari usaha bumdes tersebut dapat dirasakan oleh seluruh lapisan masyarakat sehingga dapat berdampak bagi kesejahteraan masyarakat desa dan meningkatkan pendapatan desa. Aktivitas BUMDes di pedesaan lebih banyak bebasis sektor pertanian dengan konsep agribisnis.

Pengembangan konsep agribisnis meningkatkan nilai tambah dan pendapatan petani skala kecil. Namun, tantangan terbesar bagi pelaku agribisnis adalah meningkatkan fungsi tata kelola dan kerangka regulasi bagi petani skala kecil dan pekerja upahan di sektor pertanian (Bissonnette, 2016). Senada dengan Savitri dan Syahza (2019), Savitri dkk (2020), sektor usaha kecil dan menengah yang terkait dengan kehidupan ekonomi sebagian besar masyarakat di pedesaan sangat vital dalam memperkuat struktur perekonomian nasional. Di sisi lain, kinerja bisnis dipengaruhi oleh strategi adaptasi, orientasi kewirausahaan, dan kebijakan pemerintah. Menurut Huang dan Liang (2018), petani di pedesaan berpartisipasi secara efektif dalam pertanian modern melalui koperasi, menentukan posisi sentral mereka dalam sistem organisasi pertanian melalui manajemen kelembagaan ekonomi. Kireyenka (2019), mengatakan, pendekatan ketahanan pangan nasional ditonjolkan dari segi kondisi, sasaran, dan tujuan pertanian. Oleh karena itu, pembangunan pertanian harus memperhatikan prioritas nasional dalam produksi, pasar konsumen dalam negeri, dan perdagangan luar negeri.

Berdasarkan uraian latar belakang, maka tujuan yang ingin dicapai dalam penelitian ini adalah mengidentifikasi kendala pengembangan BUMDes di Kecamatan Pangkalan Lesung dan mengidentifikasi kekuatan, kelemahan, ancaman dan peluang untuk pengembangan Bumdes Di Kecamatan Pangkalan Lesung sehingga dapat merumuskan alternatif strategi pengembangan yang tepat untuk diterapkan melalui analisis SWOT. Manfaat dari penelitian ini diharapkan dapat dapat dijadikan rekomendasi agar BUMDes di Kecamatan Pangkalan Lesung dapat lebih optimal dalam melaksanakan program usahanya dan sebagai bahan 
bagi pengembangan ilmu pengetahuan dan pengalaman yang diperoleh dari perkuliahan serta menambah wawasan penulis.

\section{METODE PENELITIAN}

Penelitian ini dilaksanakan di Kecamatan Pangkalan Lesung Kabupaten Pelalawan, penelitian ini bertujuan untuk merumuskan strategi pengembangan BUMDes di pedesaan. Responden pada penelitian adalah pengurus BUMDes, masyarakat sekitar dan anggota BUMDes. Pengumpulkan data dilakukan dengan cara wawancara demgan pengurus, sedang untuk masyarakat informasi diperoleh menggunakan kuesioner. Data yang terkumpul ditabulasi sesuai dengan kebutuhan penelitian, kemudian dianalisis secara diskriptif menggunakan teknik analisis SWOT. Analisis terdiri dari faktor internal dan eksternal. Keputusan diambil dari hasil kalaborasi faktor internal dan eksternal tersebut.

\section{HASIL DAN PEMBAHASAN}

\section{Identifikasi Faktor Internal dan Eksternal}

Berdasarkan Tabel 1, hasil analisis lingkungan internal dan eksternal pada BUMDes di Kecamatan Pangkalan Lesung. Faktor-faktor strategis yang dapat diidentifikasi menjadi kekuatan (strengths), kelemahan (weakness), peluang (Opportunities) dan ancaman (Threats) disajikan dianalisis dalam bentuk tabel IFAS dan EFAS. Untuk mendapatkan seberapa besar kemampuan Faktor strategis Internal dan Eksternal setelahnya total IFAS dan EFAS akan disajikan dalam bentuk tabel IE Matriks. Tabel tersebut untuk menentukan posisioning BUMDes di Kecamatan Pangkalan Lesung. Setelah mendapatkan posisioning BUMDes selanjutnya untuk mendapatkan ternative strategi pengembangan yang dibutuhkan maka dianalisis kembali dalam bentuk Matriks SWOT yang mendapatkan empat sel alternative strategi dan penentuan prioritas startegi sesuai dengan posisioning yang telah didapatkan. 
Tabel 1. Diagram SWOT Pengembanagan BUMDes di Pedesaan

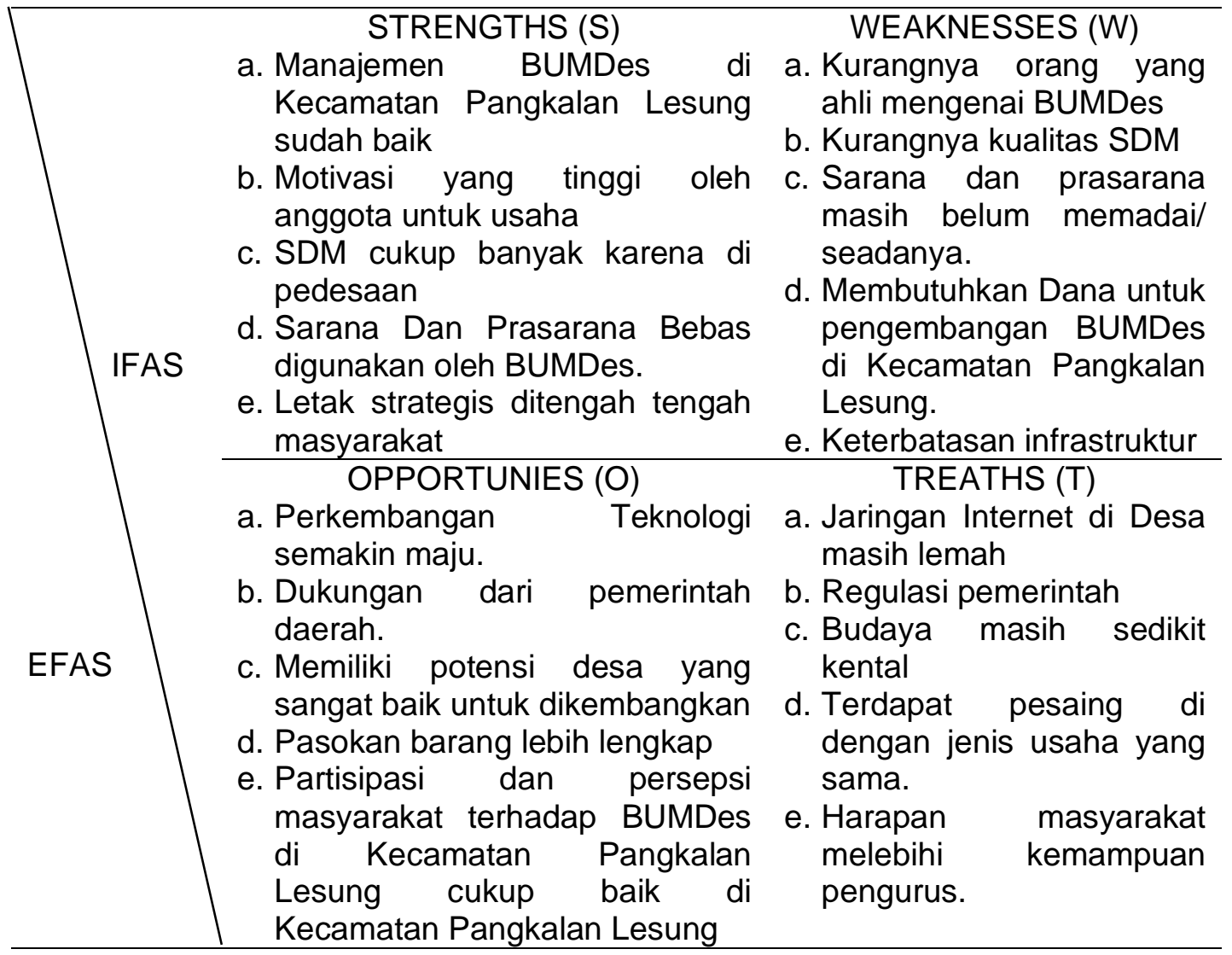

\section{Analisis IFAS}

Hasil identifikasi faktor-faktor strategi internal BUMDes dan pemberian bobot serta rating diperoleh hasil analisis yang disajikan pada Tabel 2. Didapat total skor sebesar 3.00 Hal ini menunjukkan bahwa BUMDes di Kecamatan Pangkalan Lesung memiliki kemampuan yang tinggi dalam memanfaatkan kekuatan untuk mengatasi kelemahan internal usaha. Kekuatan tersebut disebabkan oleh faktor sumberdaya manusia pedesaan cukup mendukung, walaupun dari sisi lain kualitasnya perlu ditingkatkan. BUMDes merupakan kelembagaan ekonomi pedesaan yang terkait dengan pemasaran produk yang ada di pedesaan.

Hasil analisis tersebut sejalan dengan penelitian yang pernah dilakukan oleh Syahza dan Indrawati (2010) menunjukkan bahwa BUMDes dan UMKM memiliki kemampuan yang tinggi dalam memanfaatkan kekuatan untuk mengatasi kelemahan internal usaha dengan total skor sebesar 3.037. Hal yang sama menurut Rangkuti (2018) bahwa total skor jauh dibawah 2.5 merupakan ciri organisasi yang lemah secara internal. Sedangkan jumlah yang jauh diatas 2.5 menunjukkan posisi internal yang kuat. 
Tabel 2. Penghitungan IFAS pada Badan Usaha Milik Desa (BUMDes) di Kecamatan Pangkalan Lesung

\begin{tabular}{|c|c|c|c|}
\hline Faktor-faktor strategis Internal & Bobot & Rating & $\begin{array}{l}\text { Bobot } x \\
\text { Rating }\end{array}$ \\
\hline \multicolumn{4}{|l|}{ Kekuatan (strength) } \\
\hline $\begin{array}{l}\text { Manajemen BUMDes di Kecamatan } \\
\text { Pangkalan Lesung sudah baik }\end{array}$ & 0.15 & 4 & 0.6 \\
\hline $\begin{array}{l}\text { 2. Motivasi yang tinggi oleh anggota untuk } \\
\text { usaha }\end{array}$ & 0.15 & 4 & 0.6 \\
\hline 3. SDM cukup banyak karena di pedesaan & 0.10 & 4 & 0.4 \\
\hline $\begin{array}{l}\text { 4. Sarana Dan Prasarana Bebas digunakan } \\
\text { oleh BUMDes }\end{array}$ & 0.05 & 4 & 0.2 \\
\hline 5. Letak strategis ditengah tengah masyaraat & 0.10 & 4 & 0.4 \\
\hline Sub Total & 0.55 & 20 & 2.2 \\
\hline \multicolumn{4}{|l|}{ Kelemahan (weakness) } \\
\hline $\begin{array}{l}\text { 1. Kurangnya orang yang ahli mengenai } \\
\text { BUMDes }\end{array}$ & 0.15 & 2 & 0.3 \\
\hline 2. Kurangnya kualitas SDM & 0.10 & 2 & 0.2 \\
\hline $\begin{array}{l}\text { 3.Sarana dan prasarana masih belum memadai/ } \\
\text { seadanya }\end{array}$ & 0.05 & 1 & 0.05 \\
\hline $\begin{array}{l}\text { 4. Membutuhkan Dana untuk pengembangan } \\
\text { BUMDes di Kecamatan Pangkalan } \\
\text { Lesung. }\end{array}$ & 0.10 & 2 & 0.2 \\
\hline 5. Keterbatasan infrastruktur & 0.05 & 1 & 0.05 \\
\hline \multirow[t]{2}{*}{ Sub Total } & 0.45 & 8 & 0.8 \\
\hline & & & 3.00 \\
\hline
\end{tabular}

\section{Analisis EFAS}

Hasil identifikasi faktor-faktor strategi eksternal BUMDes di Kecamatan Pangkalan Lesung dan pemberian bobot serta rating diperoleh hasil analisis yang disajikan pada Tabel 3 didapat total skor sebesar 3.52. Hal tersebut menunjukkan bahwa BUMDes di Kecamatan Pangkalan Lesung memiliki kemampuan yang tinggi dalam memanfaatkan peluang dan menghindari ancaman yang ada. Hal yang sama menurut Rangkuti (2018) bahwa total skor 1.0 menunjukkan bahwa strategi usaha tidak memanfaatkan peluang atau menghindari ancaman eksternal.

Tabel 3. Penghitungan EFAS pada Badan Usaha Milik Desa (BUMDes) di Kecamatan Pangkalan Lesung

\begin{tabular}{|c|c|c|c|}
\hline Faktor-faktor strategis Eksternal & Bobot & Rating & $\begin{array}{l}\text { Bobot } x \\
\text { Rating }\end{array}$ \\
\hline \multicolumn{4}{|l|}{ Peluang (Opportunities ) } \\
\hline 1. Perkembangan Teknologi semakin maju & 0.20 & 4 & 0.8 \\
\hline 2. Dukungan dari pemerintah daerah & 0.15 & 4 & 0.6 \\
\hline $\begin{array}{l}\text { 3. Memiliki potensi desa yang sangat baik untuk } \\
\text { dikembangkan }\end{array}$ & 0.20 & 4 & 0.8 \\
\hline 4. Pasokan barang lebih lengkap & 0.15 & 4 & 0.6 \\
\hline $\begin{array}{l}\text { 5. Partisipasi masyarakat di Kecamatan } \\
\text { Pangkalan Lesung cukup baik dan persepsi }\end{array}$ & 0.10 & 4 & 0.4 \\
\hline
\end{tabular}


terhadap BUMDes di Kecamatan Pangkalan

Lesung

\begin{tabular}{|c|c|c|c|}
\hline Sub Total & 0.8 & 20 & 3.2 \\
\hline \multicolumn{4}{|l|}{ Ancaman (Threats ) } \\
\hline 1. Jaringan Internet di Desa masih lemah & 0.02 & 2 & 0.04 \\
\hline $\begin{array}{l}\text { 2. Terdapat pesaing di dengan jenis usaha yang } \\
\text { sama }\end{array}$ & 0.05 & 2 & 0.1 \\
\hline 3. Regulasi pemerintah & 0.05 & 2 & 0.1 \\
\hline 4. Budaya masih sedikit kental & 0.05 & 1 & 0.05 \\
\hline $\begin{array}{l}\text { 5. Harapan masyarakat melebihi kemampuan } \\
\text { pengurus }\end{array}$ & 0.03 & 1 & 0.03 \\
\hline Sub Total & 0.2 & 8 & 0.32 \\
\hline TOTAL & & & 3.52 \\
\hline
\end{tabular}

\section{Analisis IE Matriks}

Tabel 4 menunjukan bahwa BUMDes di Kecamatan Pangkalan Lesung memiliki potensi pengembangan. Kondisi tersebut dapat diketahui bahwa faktor internal dan eksternal lebih menguntungkan dan berpeluang untuk berkembang. Darai data yang dianalisis, BUMDes berada pada posisi I yakni masa pertumbuhan. Posisi ini nantinya menentukan strategi yang dimiliki BUMDes untuk bisa dikembangkan melalui pemilihan alternative strategi dimana ditentukan melalui perhitungan matrik SWOT setelahnya.

Tabel 4. Internal-Eksternal Matriks

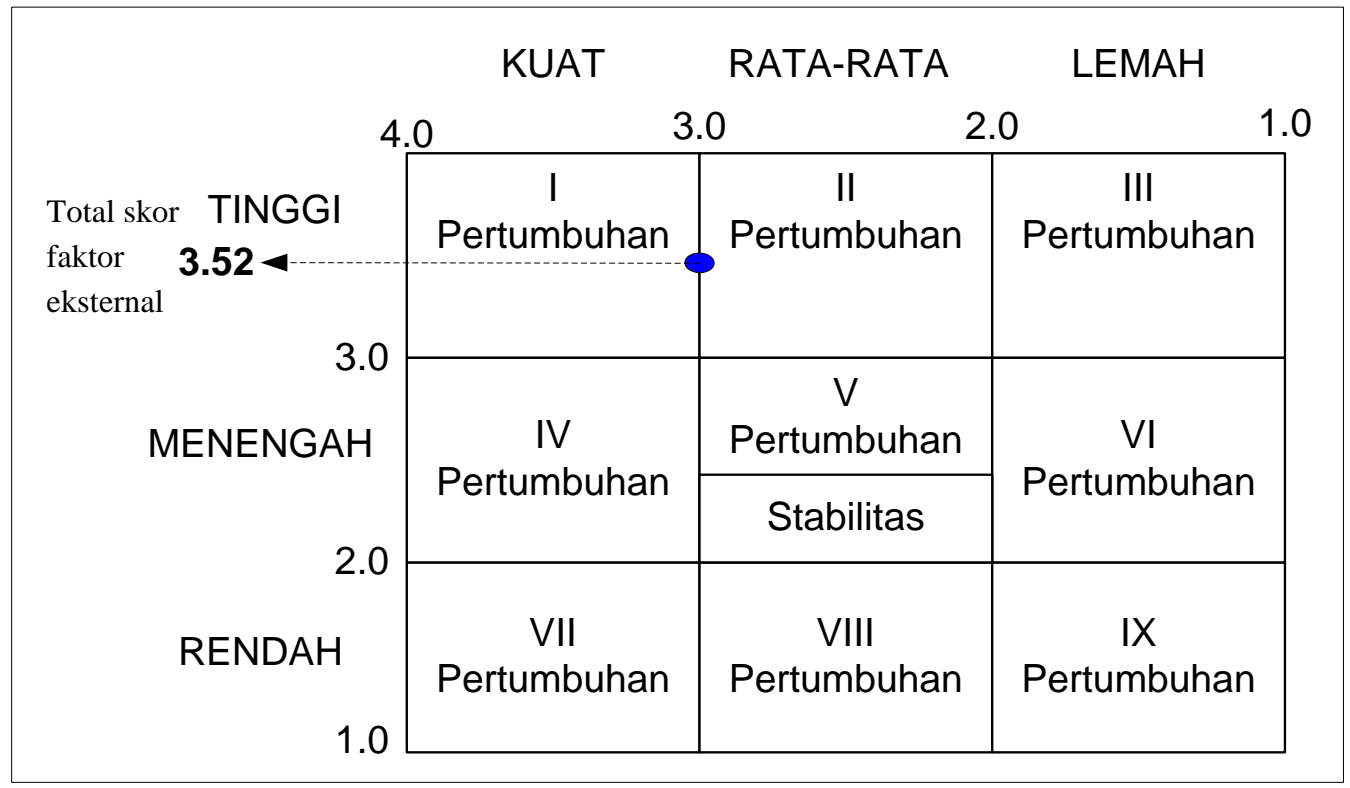

\section{Keterangan:}

I : Strategi konsentrasi melalui integrasi vertikal.

II : Strategi konsentrasi melalui integrasi horizontal.

III : Strategi turnaround

IV : Strategi stabilitas.

V : Strategi konsentrasi melalui integrasi horizontal atau stabilitas (tidak ada perubahan laba)

VI : Strategi divestasi 
VII : Strategi diversifikasi konsentrik

VIII : Strategi diversifikasi konglomerat

IX : Strategi likuidasi atau bangkrut.

\section{Analisis Matriks SWOT}

Analisis matriks SWOT menggunakan data yang telah diperoleh dari matriks IFAS dan EFAS. Empat strategi utama yang disarankan yaitu strategi S-O (strength and opportunities), W-O (weakness and opportunities), S-T (strength and threats) dan W-T (weakness and threats). Berdasarkan hasil analisis matriks SWOT pada BUMDes diperoleh empat alternatif strategi yang dihasilkan dari satu strategi S-O, satu strategi ST, satu strategi W-O dan satu strategi W-T. Hasil analisis matriks SWOT pada BUMDes di Kecamatan Pangkalan Lesung dapat dilihat pada Tabel 5.

Tabel 5. Matriks SWOT Potensi Pengembangan BUMDes

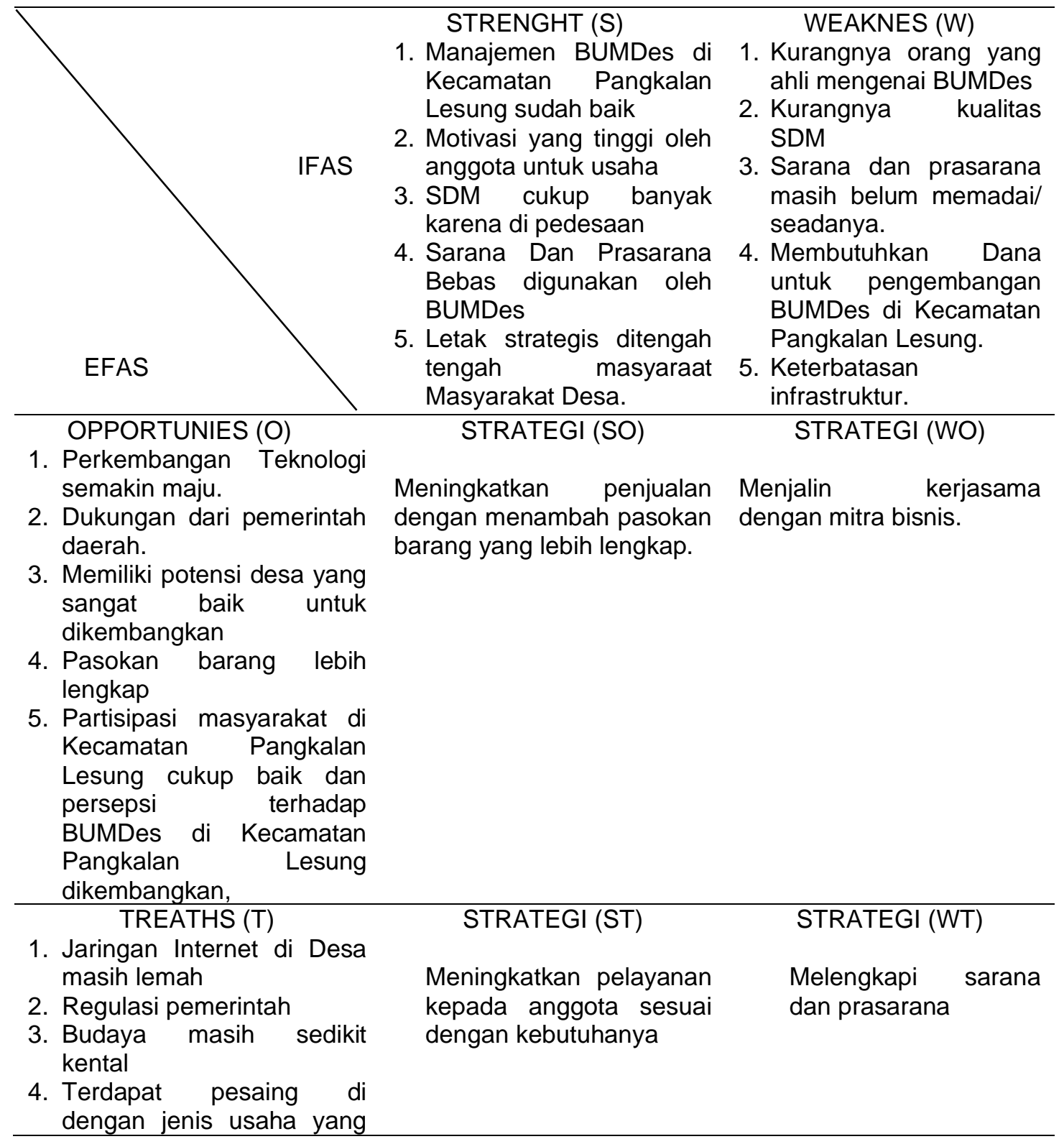


sama

5. Harapan melebihi pengurus. masyarakat

kemampuan

Menurut Rangkuti (2018) alat yang dipakai untuk menyusun faktor-faktor strategis perusahaan adalah matriks SWOT. Matriks ini dapat menggambarkan secara jelas bagaimana peluang dan ancaman eksternal yang dihadapi perusahaan dapat disesuaikan dengan kekuatan dan kelemahan yang dimilikinya. Matriks ini dapat menghasilkan empat sel kemungkinan alternatif strategis.

a. Strategi SO Strategi ini dibuat berdasarkan jalan pikiran perusahaan, yaitu dengan memanfaatkan seluruh kekuatan untuk merebut dan memanfaatkan peluang sebesar besarnya.

b. Strategi ST Strategi dalam menggunakan kekuatan yang dimiliki perusahaan untuk mengatasi ancaman.

c. Strategi WO Strategi ini diterapkan berdasarkan pemanfaatan peluang yang ada dengan cara meminimalkan kelemahan yang ada.

d. Strategi WT Strategi ini berupaya meminimalkan kelemahan yang ada serta menghindari ancaman.

Alternative yang dihasilkan dari empat sel kemungkinan alternative strategi di BUMDes Kecamatan Pangkalan Lesung yaitu, meningkatkan penjualan dengan menambah pasokan barang yang lebih lengkap guna, menjalin kerjasama dengan mitra bisnis, meningkatkan pelayanan kepada anggota sesuai dengan kebutuhanya, dan melengkapi sarana dan prasarana. Keempat alternative yang dipilih semuanya berdasarkan kebutuhan yang dipilih dan sesuai berdasarkan posisi yang sangat baik dan kuat secara lingkungan internal dan lingkungan eksternal guna pengembangan BUMDes di Kecamatan Pangkalan Lesung yang didapat setelah menganalisis faktor-faktor internal dan eksternal BUMDes. Aktivitas BUMDes tersebut dapat dilakukan dengan melibatkan masyarakat sekitarnya di pedesaan. Masyarakat diberikan hak untuk ikut bergabung pada usaha BUMDes melalui penanaman modal atau investasi. Kebijakan pengembangan BUMDes merupakan peluang usaha ekonomi bagi masyarakat petani di pedesaan.

Percepatan ekonomi di pedesaan melalui pengembangan BUMDes yang berbasis pengembangan produk unggulan masyrakat pedesaan. Pengembangan komoditas unggulan di daerah akan membuka peluang usaha bagi masyarakat terutama di pedesaan. Menurut Syahza dkk (2018), suatu peluang usaha akan menjadi sumber pendapatan yang memberikan tambahan penghasilan kepada masyarakat jika mampu menangkap peluang usaha yang potensial dikembangkan menjadi suatu kegiatan usaha yang nyata. Dengan demikian kemampuan masyarakat memanfaatkan peluang yang ada akan dipengaruhi oleh kemampuan masyarakat dalam menangkap peluang itu sendiri. Hal kedua adalah kemampuan mengorganisir sumberdaya yang dimiliki sedemikian rupa sehingga peluang yang potensial menjadi usaha yang secara aktual dapat dioperasikan. Dari sisi lain hasil penelitian Indrawati dkk (2020) menemukan lima faktor penghambat inovasi teknologi di daerah yaitu dukungan pemerintah, kualitas sumber daya manusia, 
pendanaan untuk inovasi teknologi, kondisi ekonomi, dan mitra usaha. Faktor pembatas terbesar tetap mendanai inovasi tersebut.

Investasi yang dilakukan oleh BUMDes berupa transportasi, mesin pengolah produk pertanian (agroindustri) di pedesaan, mesin dan alat pertanian harus berupa penanaman modal atas nama anggota. Artinya setiap anggota mempunyai saham kepemilikan aset BUMDes. Dengan demikian konsep agroestat di pedesaan dapat berkembang (Syahza, 2019). BUMDes juga berperan sebagai penyedia kredit yang diperoleh dari lembaga perkreditan dan pengusaha. Pemberian kredit ini didasarkan kepada bentuk usaha pertanian yang mengembangkan komoditi unggulan dan punya peluang pasar. Tingkat pengembalian kredit oleh petani dapat dilakukan melalui pemotongan penjualan hasil pertanian kepada BUMDes (Syahza dkk, 2021). Hasil penelitian Gaudreau, terdapat kecenderungan kegiatan agribisnis yang dikelola oleh perusahaan perusahaan multinasional relatif sedikit. Dari sisi lain masih terbatasnya pasokan dari pergerakan pangan lokal. Untuk mengembangkan sektor pertanian perlu dukungan dari pemilik modal. Konsep agribisnis harus melibatkan berbagai pihak untuk membangun sitem yang terintegrasi (Gaudreau, 2019). Surya dkk (2021) Sudah seharusnya konsep integrasi sistem dalam pengembangan kawasan agropolitan berbasis keberlanjutan ekosistem dan pertumbuhan ekonomi regional di negara berkembang.

Penelitian yang pernah dilakukan oleh Pradini (2020) menunjukan hal yang sama posisi BUMDes menggambarkan BUMDes Surya Sejahtera berdasarkan posisi yang sangat baik dan kuat secara lingkungan internal dan lingkungan eksternal BUMDes Surya Sejahtera cenderung pada strategi SO. Hal ini dikarenakan dari pengamatan lingkungan internal dan eksternal, BUMDes Surya Sejahtera memiliki banyak kekuatan dan banyak peluang. Pada penelitian yang dilakukan Efendi (2019) mengungkapkan bahwa untuk pengembagan BUMDes yang perlu dilakukan atau strategi yang digunakan adalah mengatasi hambatan yang dialami BUMDes selama pelaksanaanya.

Pembangunan BUMDes sangat dibutuhkan oleh masyarakat di pedesaan. BUMdes dapat berfungsi sebagai lembaga yang mampu membantu pemasaran produk pertanian di pedesaan. Hasil penelitian Syahza dkk (2021), BUMDes merupakan inovatif pemasaran hasil pertanian untuk petani skala kecil dalam rangka meningkatkan kesejahteraan masyarakat pedesaan. Perlu dibangun kemitraan berbasis agribisnis yang melibatkan kelembagaan ekonomi masyarakat. Kelembagaan tersebut termasuk Badan Usaha Milik Desa (BUMDes), lembaga perkreditan, pengusaha petani, serta usaha mikro, kecil dan menengah (UMKM). Potensi pengembangan UKM bekerjasama dengan BUMDes akan memberikan nilai tambah bagi pelaku UKM, terutama produk hasil olahan berbasis pertanian (Julianti dkk, 2018). Menurut Saparita dkk (2019), ekonomi pedesaan akan cepat berkembang jika disandingkan dengan program BUMDes, terutama produk unggulan desa. Selanjutnya Basuki (2020), peran UMKM sangat besar terhadap peningkatan pendapatan masyarakat terutama di daerah pedesaan. Sudah seharusnya UMKM bermitra dengan BUMDes untuk percepatan ekonomimpedesaan. 
BUMDes adalah usaha berbasis pedesaan berbadan hukum yang dikelola oleh pemerintah desa dalam rangka menciptakan nilai tambah hasil pertanian masyarakat. Sejalan dengan hasil penelitian Savitri dkk (2019), Savitri dkk (2020), Sektor usaha kecil dan menengah memegang peranan penting dalam memperkuat struktur perekonomian nasional. Sektor tersebut terkait dengan kehidupan ekonomi sebagian besar masyarakat Indonesia. Strategi adaptasi, orientasi kewirausahaan, dan kebijakan pemerintah mempengaruhi kinerja usaha.

\section{KESIMPULAN}

Dalam upaya percepatan ekonomi di pedesaan sangat diperlukan kelembagaan yang menunjang, terutama untuk pengembangan sektor pertanian dan produk turunannya. Program pemerintah pengembangan BUMDes di setiap desa sangat terkait dengan program peningkatan ekonomi masyrakat. Upaya pengembangan BUMDes di Kecamatan Pangkalan Lesung dapat dilakukan dengan 4 alternatif strategi pengembangan usaha. Prioritas utama untuk pengembangan BUMDes yaitu, meningkatkan penjualan dengan menambah pasokan barang yang lebih lengkap, menjalin kerjasama dengan mitra bisnis, dan meningkatkan pelayanan kepada anggota sesuai dengan kebutuhanya. Bagi pengurus BUMDes, diharapkan menjadi salah satu bahan informasi dalam menyusun perencanaan kegiatan BUMDes di Kecamatan Pangkalan Lesung dalam bentuk program baik dalam jangka pendek, menengah maupunjangka panjang. Bagi masyarakat diharapkan semakin meningkatnya partisipasi dalam program BUMDes. Bagi pemerintah daerah diharapkan tetap membantu BUMDes menfasilitasi melakukan kerjasama dengan mitra bisnis, serta tetap melakukan pembinaan dan pengawasan terhadap perkembangan BUMDes di pedesaan. Selanjutanya bagi peneliti selanjutnya, diharapkan untuk melakukan peneltian yang sama dengan terutama berkaitan dengan implementasi strategi pengembangan BUMDes (dambentuk tantangan dan efektivitasnya).

\section{DAFTAR PUSTAKA}

1) Basuki, S. (2020). Pemanfaatan perjanjian perdagangan internasional melalui pemberdayaan UMKM oleh FTA Center Jakarta periode 2018-2019. Riau Journal of Empowerment, Vol 3, No 3, 149-160. https://doi.org/10.31258/raje.3.3.149-160

2) Bissonnette, J. F. (2016). Is oil palm agribusiness a sustainable development option for Indonesia? A review of issues and options. Canadian Journal of Development Studies. Vol 37 No 4, pp 446-465. https://doi.org/10.1080/02255189.2016.1202101

3) Efendi, Syahrul. (2019). "Strategi Pengembangan Usaha Milik Desa Oleh Pemerintah Desa Rajadesa Kecamatan Rajadesa". Jurnal IImiah IImu Administrasi Negara, Volume 6 Nomor 4, Bulan Desember Tahun 2019. (online) https://jurnal.unigal.ac.id/index.php/dinamika/article/view/3102, diakses pada tanggal 02 April 2021 pukul 23.10 WIB.

4) Fitriska, Kateria. (2017). "Strategi Pengembangan Badan Usaha Milik Desa Dalam Meningkatkan Kesejahteraan Masyarakat di Desa Lancang Kuning Kecamatan Bintan Utara". Jurnal IImu Administrasi Negara (JUAN), Vol. 5 No. 2 November Tahun 2017. 
(online) https://ojs.umrah.ac.id/index.php/juan/article/view/700/464, diakses pada tanggal 02 April 2021 pukul 22.16 WIB.

5) Gaudreau, M. (2019). State food security and people's food sovereignty: competing visions of agriculture in China. Canadian Journal of Development Studies. Volume 40, Number 1. Pages Pages 12-28. https://doi.org/10.1080/02255189.2017.1410470

6) Huang, Z. and Liang, Q. (2018), "Agricultural organizations and the role of farmer cooperatives in China since 1978: past and future", China Agricultural Economic Review, Vol. 10 No. 1, pp. 48-64. https://doi.org/10.1108/CAER-10-2017-0189

7) Indrawati, H., Caska, and Suarman. (2020). "Barriers to technological innovations of SMEs: how to solve them?", International Journal of Innovation Science, 12(5): 545564. https://doi.org/10.1108/IJIS-04-2020-0049

8) Julianti, E., Ridwansyah, T. Karo-Karo, dan Halimatuddahliana. (2018). Diversifikasi produk melalui pemanfaatan tepung umbi-umbian lokal sebagai pengganti terigu pada UKM produk bakery di Kota Binjai. Riau Journal of Empowerment, Vol 1, No 2: 75-83 https://doi.org/10.31258/raje.1.2.10

9) Kireyenka, N. (2019). "Agrarian Sector: Trends, Scenarios, Policy", Sergi, B.S. (Ed.) Modeling Economic Growth in Contemporary Belarus (Entrepreneurship and Global Economic Growth), Emerald Publishing Limited, pp 129-146. https://doi.org/10.1108/978-1-83867-695-720191009

10) Peraturan Menteri Pembangunan Daerah Tertinggal, dan Transmigrasi Republik Indonesia, Nomor 4 tahun 2015, tentang Pendirian, Pengurusan dan Pengelolaan, dan Pembubaran Badan Usaha Mllik Desa.

11) Pradini, Regia Nadila. (2010). "Strategi Pengembangan Badan Usaha Milik Desa (Bumdes) Di Desa Kedungturi Kabupaten Sidoarjo". Jurnal Pemerintahan dan Keamanan Publik, (JP dan KP) Vol. 2, No. 1, Februari 2020: 57-67. (online) http://ejournal.ipdn.ac.id/JPKP/article/view/1000, diakses pada tanggal 12 Februari 2021 pukul 22.48 WIB.

12) Rangkuti, Freddy. (2018). Analisis SWOT Teknik Membedah Kasus Bisnis. Jakarta: PT. Gramedia.

13) Saparita, R., E. W. Hidajat, \& E. K. Apriliyadi. (2019). Pengembangan ekonomi desa penghasil kopi melalui pemanfaatan ilmu pengetahuan dan teknologi di Kabupaten Belu. Riau Journal of Empowerment, Vol 2, No 2: 81-91 https://doi.org/10.31258/raje.2.2.81-91

14) Savitri, E. and Syahza, A. (2019). Effect Of Human Capital And Competitive Strategies Against The Financial Performance Of Small And Medium Enterprises. International Journal of Scientific \& Technology Research, Volume 8, Issue 04. Page 86-92. https://www.ijstr.org/paper-references.php?ref=IJSTR-0419-20104

15) Savitri, E., Abdullah, N. H. N., Said, J., Syahza, A., Musfialdy. (2020). How supply chain moderates the relationship of entrepreneurial orientation, adaptability strategy and government interference with performance? International Journal of Supply Chain Management, Vol. 9, No. 4, pp 355-362.

https://ojs.excelingtech.co.uk/index.php/IJSCM/article/view/5263

16) Savitri, E., Nur DP, E., Syahza, A. (2021). Can innovation mediate the effect of adaptability, entrepreneurial orientation on business performance? Management Science Letters, Volume 11 Number 8, pages 2301-2312.

https://doi.org/10.5267/j.msl.2021.3.014

17) Sulaksana, Jaka dan Irni Nuryanti. (2019). "Strategi Pengembangan Badan Usaha Milik Desa (Bumdes) Kasus Di Bumdes Mitra Sejahtera Desa Cibunut Kecamatan Argapura Kabupaten Majalengka". Jurnal Ekonomi Pertanian dan Agribisnis (JEPA), Volume 3, Nomor 2 (2019): 348-359. (online) https://jepa.ub.ac.id/index.php/jepa/article/view/192, diakses pada tanggal 12 Maret 2021 pukul 16.44 WIB. 
18) Surya, B., Saleh, H., Hamsina, H. (2021). Rural Agribusiness-based Agropolitan Area Development and Environmental Management Sustainability: Regional Economic Growth Perspectives. International Journal of Energy Economics and Policy, Volume 11, Number 1. https://doi.org/10.32479/ijeep.10184

19) Syahza, Almasdi dan Henny Indrawati. (2010). "Pemberdayaan Koperasi Berbasis Agribisnis Di Daerah Pedesaan”. Jurnal Sosiohumaniora, Vol. 12, No. 3, November 2010 : 207-220. (online).

http://jurnal.unpad.ac.id/sosiohumaniora/article/view/11551/5341, diakses pada tanggal 12 Februari 2021 pukul 23.15 WIB.

20) Syahza, Almasdi dan Suarman. (2013). "Strategi Pengembangan Daerah Tertinggal Dalam Upaya Percepatan Pembangunan Ekonomi Pedesaan". Jurnal Ekonomi Pembangunan, Volume 14 Nomor 1, Juni 2013, hlm. 126-139. (online) https://fkip.unri.ac.id/wp-content/uploads/2019/03/Strategi-Pengembangan-DaerahTertinggal-Dalam-Upaya-Percepatan Pembangunan-Pedesaan-2013.pdf, diakses pada tanggal 12 Februari 2021 pukul 24.09 WIB.

21) Syahza, A., Bakce, D. and Asmit, B. (2018). "Natural rubber institutional arrangement in efforts to accelerate rural economic development in the province of Riau", International Journal of Law and Management, Vol. 60 No. 6, pp. 1509-1521. https://doi.org/10.1108/IJLMA-10-2017-0257

22) Syahza, A. (2019). "The potential of environmental impact as a result of the development of palm oil plantation", Management of Environmental Quality, Vol. 30 No. 5, pp. 1072-1094. https://doi.org/10.1108/MEQ-11-2018-0190

23) Syahza, A ., Suwondo., Bakce, D., Nasrul, B., Mustofa, R. (2020). Utilization of Peatlands Based on Local Wisdom and Community Welfare in Riau Province, Indonesia. International Journal of Sustainable Development and Planning. Vol. 15, No. 7, pages. 1119-1126. https://doi.org/10.18280/ijsdp.150716

24) Syahza, A ., Savitri, E., Asmitc, B., Meiwanda, G., (2021). Small-scale agricultural product marketing innovation through BUMDes and MSMEs empowerment in coastal areas, Management Science Letters, Volume 11 Number 8, pages 22912300. https://doi.org/10.5267/j.msl.2021.3.015 